\title{
Vozes institucionais e os discursos de dominação: análise dos grandes projetos hidrelétricos na Amazônia'
}

\section{Institutional voices and discourses of domination: analysis of hydroelectric dam projects in the brazilian amazon}

\author{
Alda Cristina Costa \\ Doutora em Ciências Sociais e Mestre em Sociologia pela Universidade Federal do Pará (UFPA), professora do Programa de Pós- \\ Graduação em Comunicação, Cultura e Amazônia (PPGCom/UFPA). \\ <aldacristinacosta@gmail.com> \\ Ivana Cláudia Oliveira \\ Doutoranda do Programa de Pós-Graduação em Desenvolvimento Sustentável do Trópico Úmido (PPGDSTU) do Núcleo de Altos \\ Estudos Amazônicos (NAEA), professora da Universidade da Amazônia (Unama). \\ <ivana.professora@gmail.com> \\ Nírvea Ravena \\ Doutora em Ciência Política pelo Instituto Universitário de Pesquisas do Rio de Janeiro. Professora do Programa de Pós- \\ Graduação em Desenvolvimento Sustentável do Trópico Úmido-PPGDSTU do Núcleo de Altos Estudos Amazônicos (NAEA/ \\ UFPA). \\ <niravena@uol.com.br>
}

\section{RESUMO}

O interesse pela Amazônia aumenta de acordo com o status que lhe é conferido no cenário econômico e geopolítico. No cenário mundial, constitui o imaginário segundo o qual é patrimônio de todos. Os projetos direcionados ao seu território baseiam-se em compromisso e discussões que passam pela sua representação simbólica de região vocacionada para o desenvolvimento sustentável. O presente artigo busca compreender as marcas discursivas das vozes institucionais, na formulação de políticas na execução dos projetos hidrelétricos na região. Tomam-se como corpus de análise 18 mensagens enviadas pelos presidentes Emilio Garrastazu Médici (1969-1974), José Sarney (1985-1990) e Luiz Inácio Lula da Silva (20032010) ao Congresso Nacional, e a partir da análise crítica do discurso observa-se que as vozes, em recortes temporal/ideológicos diferentes, são construídas num discurso repetitivo e tecnocrático, com representações de eficiência e competência, produzidas para legitimar a dominação.

Palavras-chave: Amazônia. Hidrelétricas. Discursos Institucionais.

\begin{abstract}
Interest in the Amazon increases according to the status given to it in the economic and geopolitical scenario. On the world stage, it is the imaginary according to which is the heritage of all. The projects targeted to its territory based on commitment and discussions that go through its symbolic representation of the area dedicated to sustainable development. This article seeks to understand the discursive marks of institutional voices in policy-making in the execution of hydroelectric projects in the region. They are taken as analysis corpus 18 messages sent by presidents Garrastazu Emilio Medici (1969-1974), José Sarney (1985-1990) and Luiz Inácio Lula da Silva (20032010) to the National Congress, and from the critical analysis of speech is observed that the voices in time / different ideological cuts, are built in a repetitive and technocratic discourse, with representations of efficiency and competence, produced to legitimize domination.
\end{abstract}

Keywords: Amazon. Hydroelectric dams. Institutional discourses.

1 Uma versão preliminar deste trabalho foi apresentada no I Seminário Internacional América Latina: políticas e conflitos contemporâneos, promovido pelo Núcleo de Altos Estudos Amazônicos, Universidade Federal do Pará (NAEA/UFPA). 


\section{INTRODUÇÃO}

Observa-se que os discursos institucionais conformam e materializam a relação de dominação sobre a região amazônica, independente de contexto histórico, econômico ou social. De acordo com Costa (2008, p. 1), o discurso atual produzido sobre a Amazônia guarda semelhanças com os discursos do colonialismo, "vista ainda hoje como exótica, subalterna, selvagem, pelo centrosul do país, as narrativas sobre a Região reforçam imagens cristalizadas de uma terra que necessita ser ocupada". Lembra ainda, que entre as cartas dos primeiros viajantes e os textos jornalísticos de hoje, pouca coisa mudou.

Na elaboração do presente artigo, tomam-se como objeto de análise as 18 mensagens enviadas ao Congresso Nacional por três presidentes da República, em períodos históricos diferentes: a ditadura militar (Emilio Garrastazu Médici - 1969 a 1974); a redemocratização (José Sarney - 1985 a 1990); e legislatura de um partido de esquerda, (Luiz Inácio Lula da Silva (2003 - 2010), conforme Tabela 1. A abordagem da pesquisa desenvolve-se na perspectiva da Análise Crítica do Discurso, que busca não somente a descrição minuciosa de um "documento-objeto", mas também da ordem do discurso de uma instituição, as formas ideológico-discursivas impostas e as relações de dominação que se determinam em relação à região Amazônica.

\begin{tabular}{ccc}
\hline \multicolumn{3}{c}{ Tabela 1: Mensagens Presidenciais } \\
\hline Presidentes & Período & Mensagens \\
\hline Emilio Garrastazu Médici & $1969-1974$ & 5 \\
José Sarney & $1985-1990$ & 5 \\
Luiz Inácio Lula da Silva & $2003-2006$ & 8 \\
\hline
\end{tabular}

Fonte: As autoras

A Análise do Discurso é tomada como método e metodologia (Phillips; Hardy, 2002), e para Maingueneau, não tem por objeto "nem a organização textual em si mesma, nem a situação de comunicação", mas deve "pensar o dispositivo de enunciação que associa uma organização textual e um lugar social determinados" (Charaudeau; Maingueneau, 2006, p. 44). Procura, portanto, "entender ou interpretar a realidade social como ela existe, desmascarando a forma em que ela é produzida" (Phillips; Hardy, 2002, p. 6).

Em Foucault (1996), a ênfase do discurso não se encontra no sujeito, nem no enunciado, mas nas formulações discursivas construídas. De modo que essas formulações discursivas são ações interacionais entre os interlocutores 
e o contexto da enunciação, remetendo a "um conjunto de regras anônimas, históricas sempre determinadas no tempo espaço, que definiram em uma dada época, e para uma área social, econômica, geográfica, ou linguística dada, as condições de exercício da função enunciativa" (Foucault, 1997, p. 43). Desse modo, as práticas discursivas se apresentam ligadas entre discurso e prática.

O discurso é ancorado em ideologias, isto é, os sujeitos se apropriam dele e o ressignificam como mascaramento da realidade, suplantando verdades, inferindo posições e, em alguns casos, conformando dominações; situação que pode ser observada nos discursos construídos nas mensagens presidenciais sobre a Amazônia, que também é cercada de um silenciamento, passando a ser tensionado de modo recente e a partir dos movimentos sociais, com especial visibilidade na internet e em redes sociais digitais.

De acordo com Orlandi (1992, 2001), o silêncio tem um sentido que é próprio dele mesmo e tem sentidos que ele adquire na sua relação com o dizível. Podemos afirmar, a partir dos conceitos de Orlandi, que o silêncio, para os objetivos de nossa pesquisa, caracteriza-se de três modos: a) a política do silêncio: que se manifesta de duas formas, o silêncio constitutivo e o silêncio local. "O silêncio constitutivo pertence à ordem de produção do sentido, representa a política do silêncio como um efeito de discurso que instala o antiimplícito, se diz x para não dizer y, apagam-se os sentidos que se quer evitar, sentidos que poderiam instalar o trabalho significativo de uma outra formação discursiva. O sentido local se manifesta através da censura, trata-se da produção do sentido como uma estratégia política de produção do interdito, do proibido, a interdição do dizer" (Orlandi, 1992, p. 75-77); b) através do silêncio, "podemos passar das palavras para as imagens e as metáforas" (Orlandi, 1992, p. 15); c) "a materialidade do silêncio está especificada na relação do imaginário com o real" (Orlandi, 1992, p. 16).

Ao discutir o papel do sujeito no discurso, Orlandi infere que ele se constitui enquanto sujeito ao mesmo tempo em que é construtor de uma realidade, modificando-a e sendo modificada por ela, ou então, "o sujeito, por sua vez, ao dizer, se significa e significa o próprio mundo. [...] Não no sentido de realizar atos, mas, porque pratica sentido, ação simbólica que intervém no real (2001, p. 44)

Na Amazônia, os projetos de geração de energia são os que têm causado grandes conflitos, disputas políticas e econômicas, principalmente pelos impactos ambientais e sociais que deixam na região, excluindo o homem local da participação nas decisões tomadas pelo poder público relativamente à gestão de políticas. Isso determina para a região um papel único de fornecedora de 
insumos para suprir as necessidades de outras regiões brasileiras, como aponta Lúcio Flávio Pinto (2012a, p. 34-35), ao afirmar que "mais de 70\% da energia que é gerada no Brasil sai dos rios" e, considerando que "os rios mais próximos aos principais centros de consumo do país, nas regiões sul e sudeste, estão com seu potencial quase esgotado", resta, portanto, à Bacia Amazônica, a maior do mundo, suprir as necessidades do país.

O estado do Pará, o segundo maior da região, tem a quarta maior hidrelétrica do mundo, mas a energia que fica no Estado, segundo Pinto, é bem menor do que a que sai para além dos seus limites. $E$, a quantidade que fica, não consegue atender toda a população, de mais de 7 milhões de habitantes. Uma parcela da população ainda supre suas necessidades de velhas usinas de óleo ou vivem sem energia durante parte do dia (Pinto, 2012a, p. 53).

\section{BREVE CONTEXTUALIZAÇÃO HISTÓRICA}

No presente artigo, escolhemos três momentos distintos da história do país: para confrontar e analisar os discursos institucionais construídos e a inserção de grandes projetos hidrelétricos na Amazônia, considerando que esses projetos obedeciam a meta maior de eletrificação do país, depois da crise do Petróleo de 1973 e da criação do Proalcool que priorizou a exploração do potencial hidráulico brasileiro com cerca de $150 \mathrm{mil} \mathrm{mw}$, 40\% dos quais identificados na Amazônia (Brasil, 1971). Os projetos hidrelétricos visavam o desenvolvimento de centros consumidores na região, além do uso industrial para exploração e benefício do alumínio e bauxita.

\section{REGIME MILITAR}

A ação mais efetiva do governo federal na Amazônia ganha corpo com os governos militares, na década de 1960, quando é lançada a "Operação Amazônia" com a finalidade de ocupação, desenvolvimento e integração da região. Um aparato institucional é viabilizado e chega-se a década de 1970 com a chancela da segurança nacional na Amazônia. A economia nacional inclui a região norte como estratégica, trazendo as transformações estruturais, iniciando uma desconcentração produtiva do centro para as periferias para concretizar a política de "integrar para não entregar" (Lourenço, 2001, p. 357).

Nessa perspectiva, Médici assume a presidência em 1969 como o terceiro presidente militar, através de eleição indireta, por indicação do Alto Comando do Exército. Na área econômica, institui o "milagre brasileiro", com o discurso político-econômico para a construção de um projeto nacional de expansão da economia brasileira apoiado no crescimento do PIB, estabilização da inflação 
e expansão industrial. De sua gestão faz parte o Plano Nacional de Integração com a previsão de obras como as rodovias Transamazônica, Cuiabá-Santarém e Manaus-Porto Velho (BRASIL, [20--]).

No governo Médici, os militares pretendiam conquistar os "vazios" sob o signo do milagre econômico. O PIB entre 1968 e 1973 (Tavares, 1975) ficou na média de $11 \%$, um dos maiores índices de crescimento da história, resultado de uma fase determinante na expansão da infraestrutura na Amazônia, principalmente das grandes rodovias que eram espinhas dorsais dos programas de colonização (Plano de Integração Nacional-PIN; Programa de Redistribuição da Terra-PROTERRA e o primeiro Plano de Desenvolvimento da Amazônia).

$\mathrm{Na}$ conclusão deste governo, a região era detentora de uma maior infraestrutura, mas não conseguia manter os índices econômicos planejados, considerando as poucas oportunidades de emprego e os graves problemas fundiários criados pelos grandes empreendimentos, que agravaram os conflitos de terra na Amazônia (Lourenço, 2001).

\section{REDEMOCRATIZAÇÃO}

A redemocratização brasileira começa com o chamado período de abertura política, iniciado no governo Geisel (1974-1979), e vai até a eleição indireta de Tancredo Neves, que morrerá antes de assumir o poder. O vice José Sarney assume o Executivo Federal, e ficará marcado pela implantação do Plano Cruzado, para combater a inflação elevadíssima, com o congelamento de preços e troca da moeda. É a década de 1980 e a região amazônica ainda repete conhecidas marcas do subdesenvolvimento: fragilidade financeira do Estado, dependente de investimentos internacionais privados para apoiar projetos na região. As grandes hidrelétricas - Tucuruí, Balbina e Samuel e os megaprojetos dos setores produtivos - Programa Grande Carajás, complexos Albrás-Alunorte e Alcoa, caracterizaram a indústria regional que tinha como objetivo principal a destinação de produtos para o mercado internacional. As grandes hidrelétricas se configuram então como fornecedoras de energia barata para esses projetos industriais minerometalúrgicos (Lourenço, 2001).

Destaca-se ainda o custo social das obras das hidrelétricas com o deslocamento de famílias, intensificação de impactos ambientais e destruição de terras férteis alagadas (Oliveira e Martins, 2005). Esses conflitos socioambientais e econômicos geram uma cobrança de retratação em espaços de discussões de políticas ambientais que começam a se ampliar nesse momento histórico. O emergente movimento ambiental impacta o governo de Sarney e, de acordo com Carvalho (2001), surgirá uma aparente mudança na postura e nos discursos 
sobre as questões ambientais e o desenvolvimento da região amazônica. Nesse período vão ser criados o Instituto Brasileiro do Meio Ambiente e dos Recursos Naturais Renováveis (Ibama), o Conselho Nacional do Meio Ambiente (Conama) e o programa governamental Nossa Natureza, tentativas iniciais de incorporação das preocupações ambientais no modelo de desenvolvimento.

\section{UM PRESIDENTE DE ESQUERDA}

Em 2003, subia ao Palácio do Planalto o trigésimo quinto presidente da República Federativa do Brasil, Luiz Inácio Lula da Silva, do Partido dos Trabalhadores (PT). Lula assumia o governo com um cenário econômico com altos índices de desemprego e declínio da renda, do consumo e da produção e na posse afirmou: "O que nós estamos vivendo hoje, neste momento, [...] pode ser resumido em poucas palavras: hoje é o dia do reencontro do Brasil consigo mesmo" (Brasil, 2003b, p. 13).

O presidente Luiz Inácio Lula da Silva foi um defensor da construção da Usina de Belo Monte, considerando a necessidade de evitar um apagão no país. Em visita realizada ao Estado do Pará, em junho de 2010, convocou os paraenses a se engajarem em uma briga nacional em defesa da Usina de Belo Monte. Como compromisso pessoal, o então presidente afirmou que a construção da hidrelétrica leva em conta os aspectos ambientais, a geração de empregos para região, e a utilização de energia limpa (Portal G1, 2010).

Aos que criticavam a obra, entre ambientalistas, especialistas e pesquisadores, lembrou da sua preocupação com a questão ambiental, fazendo referência com o passado, que pouco se atentou para o problema. Afirmou que: "aprendemos a não repetir as mazelas do que foi feito na década de 60, na década de 70, quando as pessoas eram simplesmente expropriadas de suas terras e ficavam ao deus-dará" (Brasil, 2010a, p. 1) e negou que Belo Monte tenha sido imposta à sociedade.

A defesa interna da exploração do potencial hidrelétrico na região, demarca o primeiro governo Lula, tendo à frente do ministério de Minas e Energia, Dilma Rousseff, defendendo firmemente a construção de grandes barragens nos rios amazônicos. A posição contrariou as recomendações da Comissão Mundial sobre Barragens listando os impactos ambientais e sociais, os altos custos de produção e as perdas nunca devidamente indenizadas às populações atingidas como principais argumentos contrários às grandes hidrelétricas (Comissão Mundial de Barragens, 2000). 


\section{A AMAZÔNIA NAS VOZES INSTITUCIONAIS}

A Amazônia assume um papel geopolítico relevante para o país, a partir do Golpe de 1964, quando são estabelecidos os discursos da segurança e do desenvolvimento. Um dos efeitos dessa política foi a criação, em 1966, da Amazônia Legal, juntamente à Sudam². Como escreve Silva (2009, p. 7), desde o período imperial e a República Velha, "a Amazônia esteve predominantemente à margem dos eixos principais da economia e da sociedade nacional. A presença do Estado nacional e das políticas públicas na região, com raras exceções, inexistiu, concretamente, em todos os sentidos".

No século XXI, a região volta a ser foco de atenções na mídia com a execução da maior obra do Programa de Aceleração do Crescimento (PAC) ${ }^{3}$ do Governo Federal a ser realizada no estado do Pará: o Usina Hidrelétrica de Belo Monte, no rio Xingu.

É importante lembrar que obras de grande porte no setor elétrico foram implementadas na década de 1970 no país, época anterior à legislação ecológica vigente, somente consolidada em 1981, quando os projetos já estavam definidos e iniciados. Com a criação da Eletronorte (1973), o Governo Federal desconsidera as características naturais da Amazônia - rios de planície com baixa declividade natural e estabelece a região como fonte de energia abundante para a transmissão por longas distâncias até os centros mais desenvolvidos do país. "A Amazônia permaneceria como fronteira ou colônia" (Pinto, 2011, p. 4).

Os primeiros 'grandes projetos'4, implantados na década de 1970, geraram sérios problemas, seja pela agressividade à natureza seja pelo pouco desenvolvimento econômico, político e social da região, levando em conta sobretudo o momento vivido pelo Brasil, quando a discussão de viabilidade desses projetos ainda era feita intramuros, deixando a sociedade à parte dos debates e das decisões.

2 Superintendência do Desenvolvimento da Amazônia é uma autarquia federal responsável pela política de incentivos fiscais para a região. Foi criada através da Lei 5.173 de 27.10.66, em substituição à Superintendência do Plano de Valorização Econômica da Amazônia - SPVEA (Lei 1.806 de 06.01.1953) (SUDAM, [20--]).

3 O PAC é um programa implementado pela União, através do Decreto 6.025, de 28 janeiro de 2007, no segundo governo do presidente Luiz Inácio Lula da Silva, e engloba um conjunto de políticas econômicas de investimentos em áreas como saneamento, habitação, transporte, energia e recursos hídricos.

$4 \quad$ Na década de 1970, foram lançados os seguintes projetos: Jari, pelo norteamericano Daniel Ludwig que incluía a Cadam, primeira fábrica de caulim da Amazônia e também a fábrica de celulose; o Projeto Grande Carajás, para exploração de minérios na região, contendo minério de ferro de alto teor, ouro, estanho, bauxita, manganês, níquel e cobre. Em seguida, para gerar energia elétrica que atendesse aos projetos de extração mineral e à industrialização da região, o governo federal lança a usina hidrelétrica de Tucuruí, quarta maior do mundo. 
Os projetos energéticos são os que têm causado grandes conflitos, disputas políticas e econômicas, principalmente pelos impactos ambientais e sociais que deixam na região e por manter um "modelo colonial" de imposição, sem escuta das vozes de especialistas ou das comunidades atingidas e envolvidas.

[...] ao longo do tempo, diversos especialistas têm se mobilizado para tornar públicas as graves consequências que o barramento do rio Xingu, em seu trecho denominado Volta Grande, poderá acarretar para a importante diversidade sociocultural e biológica da região [...] alertando a sociedade para os graves riscos sociais e ambientais inerentes ao projeto Belo Monte (Hernández; Magalhães, 2011, p. 82).

O projeto do Complexo Hidrelétrico de Belo Monte foi considerado obra prioritária do Governo Federal no desenvolvimento do setor energético brasileiro e tem no histórico mais de 30 anos de polêmica para implantação. As discussões têm início em 1975, quando a recém-criada empresa Centrais Elétricas do Brasil S/A (Eletronorte), inicia os Estudos de Inventário Hidrelétrico da Bacia Hidrográfica do Rio Xingu, para mapear o rio e os afluentes mais favoráveis para barramentos. Na década de 1980, o relatório é finalizado com a previsão de sete barramentos e a Eletronorte inicia os estudos de viabilidade técnica e econômica do chamado complexo de Altamira.

A primeira visibilidade dos problemas ambientais da construção de Belo Monte foi na esfera internacional: em 1988, na Universidade da Flórida, em Miami, Estados Unidos, o líder Kaiapó Paulinho Paiakan, Kube-IKaiapó e o etnobiólogo Darrel Posey, do Museu Paraense Emilio Goeldi, relataram no simpósio sobre manejo adequado de Florestas Tropicais, a indignação quanto à decisão do Banco Mundial de "financiar um projeto de hidrelétricas no Xingu que inundaria 7 milhões de hectares e desalojaria 13 grupos indígenas. Apesar de serem diretamente atingidos, os índios não tinham sido consultados" (Xingu Vivo, s.d.).

Depois de tornar público os problemas, os índios receberam apoio do Centro Ecumênico de Documentação e Informação (CEDI) $)^{5}$ e realizaram o Primeiro Encontro dos Povos Indígenas do Xingu, em fevereiro de 1989, no município de Altamira (PA), reunindo cerca de três mil pessoas, entre elas, 650 índios de diferentes etnias, 300 ambientalistas, 150 jornalistas de vários países e

5 Uma das organizações que originou o Instituto Socioambiental, que incorporou o patrimônio material e imaterial de 15 anos de experiência do programa Povos Indígenas no Brasil, do CEDI, e o Núcleo de Direito Indígenas (NDI), de Brasília. Organizações de atuação reconhecida nas questões dos direitos indígenas do Brasil. 
autoridades políticas. Esse encontro ficou mundialmente conhecido pela cena em que a índia Tuíra, prima de Paiakan, encosta a lâmina de um facão no rosto do então diretor da Eletronorte, José Antônio Muniz Lopes.

As manifestações a partir dessa ação não pararam mais. Ao longo dos anos diversos pesquisadores têm realizado estudos apontando as lacunas e prejuízos advindos com a implantação dessa usina. Um desses relatórios denominado de Painel de Especialistas (Santos; Hernández, 2009) ${ }^{6}$ foi produzido tendo como base a apresentação dos Estudos de Impacto Ambiental (EIA) que a Eletrobrás entregou ao IBAMA, no processo de licenciamento para a implantação de Belo Monte, estudo crítico de diversas instituições de ensino e pesquisa, evidenciando para a sociedade as falhas, omissões e lacunas dos estudos com a finalidade de subsidiar um processo de decisão, "pautado pelo debate público - sério e democrático". No documento, os pesquisadores com larga experiência científica na Amazônia, apresentam considerações extremamente graves em relação à qualidade e à confiabilidade dos dados do EIA, destacando a dimensão dos impactos e seus potenciais programas para atenuar o problema que será gerado.

Na proposta de execução do projeto da usina (Cartilha, 2011), está previsto o acréscimo de mais 11.233 MW de capacidade instalada e 4.571 MW de energia assegurada, devendo abastecer cerca de 18 milhões de residências ou 60 milhões de pessoas. O Complexo Hidrelétrico atingirá 11 municípios paraenses pertencentes à área denominada Volta Grande do Rio Xingu, porém menos de $10 \%$ da energia produzida será utilizada em território paraense. Estudo realizado pela Universidade Federal do Pará, em 2011, confronta o Relatório de Impacto Ambiental (RIMA) que totaliza 16,4 mil pessoas atingidas. A pesquisa aponta que esse quantitativo é aproximadamente 55\% maior, somando cerca de 25,4 mil moradores impactados com a formação do lago da Usina (UFPA, 2010).

\section{DISCURSO, PODER E DOMINAÇÃO}

O discurso sobre a região se mostra ressignificado nos diferentes momentos analisados. A correlação de forças não é a mesma de 1975, quando se vivia uma ditadura, mas o Estado, como afirma Pinto (2012a, p. 34), "personificado na União Federal, pode muito. Talvez ainda mais do que a sociedade", pelos instrumentos legais e políticos de que dispõem para'controlar' o processo de realização das obras. Para o jornalista, é "por causa da parte mais desenvolvida do Brasil que ainda se projeta, como no passado, grandes

6 Formados por antropólogos, sociólogos, biólogos, engenheiros eletricistas e mecânicos, economistas, geógrafos, especialistas em energia, ecólogos, ictiólogos, hidrólogos, etnólogos, zoólogos, cientistas políticos e pesquisadores da área de saúde pública e da assistência social. 
barragens para a Amazônia". E afirma que obras dessa natureza "além dos problemas que acarretam à natureza e aos habitantes das margens dos cursos d'água, exigem a construção de extensas linhas de transmissão" de energia em alta-tensão" (Pinto, 2012a, p. 35, grifo nosso).

De acordo com o contexto histórico e os instrumentos legais e políticos disponíveis, o discurso ganha novas nuances, mas realiza o mesmo tratamento de dominação e poder do passado para a Amazônia, como pode ser observado nestes fragmentos de discursos presidenciais que guardam 30 anos de intervalo temporal e estão separados por sete mandatos.

O desenvolvimento brasileiro vem-se operando com base, principalmente numa economia moderna e na arrancada para o desbravamento da Amazônia... (Médici, 1973, p. 14, grifo nosso).

Portanto, a nova inserção da Amazônia no desenvolvimento nacional e no contexto internacional requer a formulação de política que tenha como referencial básico uma nova visão espacial do território amazônico [...]. Requer também a convergência de objetivos e a coordenação na formulação e na implementação das políticas nacional e regional de desenvolvimento, de modo que propicie $a$ exploração da riqueza de sua biossociodiversidade em benefício não só do Brasil mas de seus habitantes (Lula, 2003, p. 188, grifo nosso).

A Amazônia do século XXI apresenta as marcas discursivas da região de 1970, como fronteira de recursos a ser explorada, espaço a ser ocupado para se integrar ao país e região fornecedora de insumos aos grandes projetos de exploração. Corrobora assim com o que afirmam Haroche, Henry, Pêcheux (1971, p. 102-103) "[...] as formações ideológicas comportam, necessariamente, como um de seus componentes, uma ou mais formações discursivas interligadas, que determinam aquilo que se pode e se deve dizer [...] a partir de uma posição dada em uma conjuntura dada".

\section{EMILIO GARRASTAZU MEDICI (1970 - 1974)}

O presidente Garrastazu Médici enviou ao Congresso Nacional cinco mensagens na sua gestão, são as mais resumidas entre as analisadas, com 100 páginas em média (Brasil, 1970, 1971, 1972, 1973, 1974). A apresentação foi organizada seguindo uma divisão em quatro áreas: política econômica e financeira; política social; política externa; e política interna e segurança. 
A Amazônia recebe de 5 a 12 citações nas primeiras Mensagens e somente na última, que faz um balanço final do governo, a região é mencionada 41 vezes por Médici.

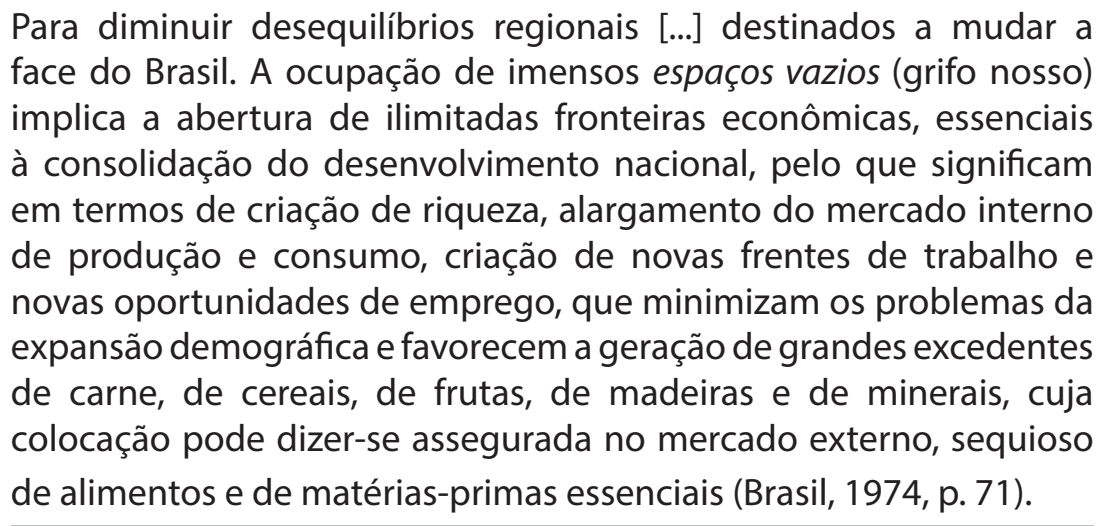

Em todos os documentos do período, o Norte do País está associado às expressões: "desbravamento", "ocupação de imensos espaços vazios" e "abertura de ilimitadas fronteiras econômicas" e o espaço destinado à região foi relatado no setor de transporte e da política econômica. Invariavelmente, o Norte é citado em ações em que os textos mencionam simultaneamente o Nordeste do País, o que explica a simplificação do espaço geográfico, anulando diferenças existentes entre as regiões. Isso implica na Amazônia ser tratada como um espaço vazio que precisa ser ocupado, e sendo fornecedora de insumos para o restante do Brasil. Em nenhum momento, a voz institucional menciona as pessoas que no território vivem.

O primeiro busca acrescer duas dimensões ao processo do desenvolvimento brasileiro: a ocupação econômica de cerca de 2 milhões de $\mathrm{km} 2$ da Amazônia e a incorporação à economia de mercado de aproximadamente 13 milhões de habitantes da região semi-árida do Nordeste (Brasil, 1971, p 17).

A Amazônia é tratada apenas como território físico e geográfico. Ou como afirma o jornalista Lúcio Flávio Pinto, "das sentenças refratárias à elucidação, do triunfalismo salvífico dos profetas do vazio" (2012a, p. 12). Nesse período, a maioria dos enunciados relativos à região está relacionada ao programa de integração nacional e aos incentivos fiscais distribuídos.

[...] a redução do desequilíbrio entre macrorregiões, objetivando, em especial, acelerar o esforço de soerguimento do Norte e do Nordeste e garantir o desenvolvimento harmônico, tanto setorial 
como geográfico, de cada uma das grandes regiões em que se divide o País. [...] a aplicação adequada e eficiente, dentro do sistema em vigor, do mecanismo de incentivos fiscais nas Regiões Norte e Nordeste. Consolidar a ocupação da Amazônia, como foi assinalado anteriormente, representa outro objetivo fundamental do Governo, possibilitando, destarte, a crescente integração daquela vasta área às demais regiões do País (Brasil, 1970, p. 47).

Somente em 1973 o governo passa a mencionar os estudos para instalação de usinas hidrelétricas na Amazônia, destacando a necessidade de maior conhecimento sobre a região para futuros projetos.

Concluíram-se os estudos que definem as possibilidades de aproveitamento hidrelétrico e equacionam o problema de suprimento de energia para os principais pólos de desenvolvimento da Amazônia; e providenciou-se a instalação de modernas e eficientes usinas térmicas nos pólos de Belém, Manaus, Porto Velho e Rio Branco, a fim de garantir o suprimento adequado de energia, até que se tornem economicamente aconselháveis alguns dos projetos hidrelétricos que são objeto de estudos mais aprofundados (Brasil, 1973, p. 44)

Porém, em nenhum momento os documentos citam a Usina Hidrelétrica de Balbina7, que teve as obras iniciadas em 1973, no rui Uatumã, próximo ao município de Presidente Figueiredo (AM), mesmo com vários manifestos de ambientalistas contra o empreendimento e seus impactos ambientais.

O mesmo silêncio se percebe em relação à Tucuruí ${ }^{8}$, localizada no sudeste do Pará, a 310 quilômetros de Belém, que começou a ser planejada em 1973, no primeiro choque do petróleo ${ }^{9}$.

\footnotetext{
7 A UHE foi construída com o objetivo inicial de reforçar o parque energético amazonense. $\mathrm{O}$ fornecimento de energia de baixo custo atenderia à população e capilarizando o interesse de empresas que pretendiam se instalar na Zona Franca de Manaus na década de 70. Mas a geração média anual de energia atingiu apenas $112 \mathrm{MW}$, e o diferencial necessário passou a ser fornecido por queima de combustíveis fósseis - nas termelétricas movidas a diesel ou gás natural. A usina supre somente 10,5\% da energia que é consumida no estado, que atinge $1.100 \mathrm{MW}$, aproximadamente (Fearnside, 1988).

8 O jornalista Lúcio Flávio Pinto (2012b, p. 778) ressalta: "A hidrelétrica de Tucuruí, no Pará, a quarta maior do mundo, ultrapassou, em setembro de 2011, um quarto de século de funcionamento. Desde 1984, ela transforma em energia as águas do $25^{\circ}$ rio mais extenso do planeta, o Tocantins, cuja área de drenagem ocupa $8 \%$ do território brasileiro, entre o Planalto Central e o litoral norte".

9 Nesse período os produtores de petróleo dos países do Oriente Médio diminuíram a produção a partir da constatação de que a substância é um bem não-renovável. Com isso, em um trimestre foi elevado o preço do barril de US\$2,90 para US\$11,65 (Folha de São Paulo, [200-]).
} 
Na Amazônia, o Comitê de Estudos Energéticos da área concluiu os trabalhos a que se propôs em fins de 1971. Presentemente o esforço de avaliação se concentra em alguns rios da margem direita do Amazonas, especialmente nas bacias do Tocantins e Xingu, cujo potencial conjunto é estimado em 40 milhões de kw (Brasil, 1974, p. 75).

O documento faz um balanço do governo, concluindo com os interesses geográficos específicos para projetos de geração de energia hidrelétrica. É a única menção que demonstra o planejamento de aproveitamento dos rios para esse tipo de geração de energia.

\section{JOSÉ SARNEY (1985-1990)}

As mensagens do Presidente José Sarney se organizaram tematicamente em quatro eixos: o modelo de desenvolvimento; perspectivas e prioridades para o ano em curso; apêndices estatísticos com levantamento da área econômica; e atividade setorial, que relatava as ações ministeriais (Brasil, 1986, 1987, 1988, 1989, 1990).

Nos anos de 1987 e 1988, os textos estão repetidos no subitem Amazônia, incluído no texto sobre as ações do Ministério do Interior, sem acréscimos de informações. O que demonstra a pouca importância com os relatos sobre a região.

É neste período que a palavra "ecológica" é referenciada pela primeira vez em mensagens oficiais dos governos federais aos congressistas: "As ações de planejamento ambiental, especialmente os programas de zoneamento ecológico-econômico, permitirão o uso mais equilibrado dos recursos naturais, preservando o lastro mais importante para a vida futura" (Brasil, 1987, p. 43).

Mas os documentos mantêm os discursos da década de 70 sobre a ocupação da Amazônia, mesmo narrando uma preocupação ambiental simultaneamente:

A política de desenvolvimento da Amazônia visa promover a ocupação ordenada da região, preservando o equilíbrio ecológico e valorizando a população. Essas diretrizes pautaram, em 1986, as ações da Superintendência do Desenvolvimento da Amazônia (SUDAM), da Superintendência da Zona Franca de Manaus (SUFRAMA), do Banco da Amazônia S.A. (BASA) e da Cia. Siderúrgica da Amazônia (SIDERAMA). A SUDAM expandiu suas atividades de planejamento regional, com a conclusão do I Plano de Desenvolvimento da Amazônia da Nova 
República (I PDA-NR), que contém as principais diretrizes para o desenvolvimento econômico e social da região (Brasil, 1987, p. 150).

A Amazônia não recebe nenhum aprofundamento informativo no texto, ainda que em todos os pronunciamentos estejam presentes enunciados narrando preocupação com a ameaça de internacionalização da região:

Outro tema que surge e que será sem dúvida o grande debate do faturo é o problema ecológico. O Brasil tem um imenso patrimônio natural a preservar. Temos a maior floresta úmida do globo. Temos grandes recursos naturais. Não podemos cometer os erros de muitos países desenvolvidos, que progrediram destruindo o meio ambiente, degradando o Planeta, de modo a ameaçar a própria vida. [...] Queremos a ajuda internacional nesse setor. Aceitaremos a cooperação científica, tecnológica, em recursos monetários e recursos humanos. Mas o dever principal é nosso. Uma coisa, contudo, jamais admitiremos: a internacionalização da Amazônia, a troca de nossa terra, da nossa soberania pela dívida ou por qualquer outra compensação (Brasil, 1989, p. XV).

A implantação, funcionamento ou planejamento de construção de usinas hidrelétricas não são evidenciados em textos mais explicativos. Estão em parágrafos curtos e quase codificados em siglas, sem detalhes, ou clareza sobre cada projeto, nas projeções para o ano de 1989, conforme observado, [...] início da construção da UHE Tucuruí E $(7 \times 330 \mathrm{MW})$ e da UHE Manso $(4 \times 53 \mathrm{MW})$, além do início de operação da UHE Balbina ( 5 × 50 MW), da UHE Samuel ( 5 × $44 \mathrm{MW})$ e das unidades 11 e 12 da UHE Tucuruí I, a cargo da ELETRONORTE; [...] (Brasil, 1989, p 91).

Percebe-se a referência constante à exploração econômica racionalizada pelo viés da preservação ambiental, mesmo que não haja nenhum aprofundamento no assunto:

No campo do planejamento regional, a Superintendência preparou estudos e elaborou diagnósticos, com a cooperação técnica da OEA, envolvendo os vales dos rios Trombetas (PA), Madeira (AM), Araguaia (AP) e Branco (RR). Foram desenvolvidos também outros estudos para a organização do espaço físico regional, incluindo a conclusão de mapeamentos de recursos geológicos, hídricos, agrícolas e florestais, a identificação das potencialidades amazônicas e a compatibilização da exploração econômica com a preservação ecológica (Brasil, 1989, p. 103). 


\section{LUIZ INÁCIO LULA DA SILVA (2003-2010)}

Já nos dois mandatos, os documentos do Governo Lula apresentam uma divisão temática mais detalhada, cujas mensagens são maiores, em média 350 páginas por ano, e com títulos que demarcam ideologicamente a proposta política de um governo para as minorias, destacando a preocupação com as questões ambientais. Os relatos estão expostos em capítulos nomeados de: Desenvolvimento Sustentável com Inclusão Social; Desenvolvimento Sustentável com Aceleração do Crescimento e Redução de Desigualdades; Cidadania e Inclusão Social; Infraestrutura; Política Exterior e Soberania; Democracia e Diálogo; e Gestão do Estado e Combate à Corrupção. Uma abordagem regional diferenciada é proposta a partir de então, mas permanece o discurso desenvolvimentista para um "objeto" com potencial de exploração (Brasil, 2003a, 2004, 2005, 2006, 2007, 2008, 2009, 2010b):

[...] a implementação do Plano Amazônia Sustentável (PAS), plano inovador de desenvolvimento regional construído de forma democrática com ampla participação dos Estados, dos Municípios e da sociedade civil, que interrompe uma longa história de planejamento autoritário para a Amazônia e propõe um tratamento diferenciado para uma região complexa e heterogênea com grande potencial econômico, diversidade social, biológica e riquezas naturais (Brasil, 2005, p. 81).

É perceptível que a denominação de região Norte é substituída definitivamente por Amazônia, sendo um item único para descrição de projetos do Governo para a região, dentro do capítulo da Integração Nacional. Mesmo relatando neste espaço os problemas peculiares que afetam a região, não há menção às consequências dos grandes projetos:

Ao longo das três últimas décadas, a Amazônia experimentou profundas mudanças estruturais na economia (industrialização), no povoamento (urbanização), na sociedade, com a emergência de novos atores locais e internacionais, e na apropriação do território, mediante a demarcação de terras indígenas, a criação de unidades de conservação ambientais e de projetos de coletividade, fruto das políticas implementadas para a região (Brasil, 2003a, p. 173).

E mesmo quando cita a ocupação desordenada, não menciona os grandes projetos que incentivaram muitos ciclos migratórios:

O crescimento urbano fez-se de forma acelerada, passando a população urbana de uma proporção de 35,7\%, em 1970, para $68,2 \%$, em 2000 , constituindo a urbanização, ao lado da mobilidade 
populacional, um dos aspectos mais dolorosos do processo de ocupação regional, uma vez que as cidades não tiveram tempo nem recursos para absorver os migrantes. Resulta, assim, que a Amazônia é uma floresta urbanizada, representando, porém, os núcleos urbanos um de seus maiores problemas ambientais (Brasil, 2003a, p. 173).

\section{A codificação quando o assunto são as hidrelétricas permanece:}

Foram outorgados 77 empreendimentos de geração de energia elétrica em 2010, referentes aos Leilões A-5/2008; A-3/2009 Energia de Reserva/2009; A-5/2010 e o Leilão da UHE Belo Monte, que acrescentarão 6.250 MW médios ao SIN, a partir de 2012. Merece destaque o Leilão da UHE Belo Monte, realizado em 20 de abril de 2010. Essa usina, localizada no Rio Xingu, terá 11.233 MW de potência instalada, com entrada em operação prevista para 2015 e investimentos da ordem de R\$ 19 bilhões (Brasil, 2010b, p. 234-235).

A Amazônia, com assuntos peculiares a serem destacados, recebe maior espaço no discurso enviado aos parlamentares, mas o silêncio sobre os grandes projetos hidrelétricos na região continua. Dentro das avaliações, é na área de transportes que acabam concentradas as menções à região. $\mathrm{E}$ mesmo com um número bem maior de citações da palavra "Amazônia", de 22 a 37 menções, não há registro das discussões ambientais que cercam os projetos governamentais. Quando a região se relaciona na mensagem à palavra "hidrelétrica" é somente para elencar o licenciamento ambiental do ano em curso:

Foram concedidas 20 licenças para Usinas Hidrelétricas de grande porte, ressaltando duas licenças prévias, três de prorrogação ou concessão de licença de instalação, 10 de renovação ou autorização para supressão da vegetação, e cinco de renovação, regularização ou retificação de licenças de operação (Brasil, 2008, p. 85).

A Hidrelétrica de Belo Monte será mencionada três vezes na Mensagem enviada em 2010, tratando de energia de reserva, leilão e obtenção da licença prévia do aproveitamento hidrelétrico da usina, listados entre várias usinas de outras regiões, sem nenhum tipo de detalhamento:

[...] devem ser ressaltados os grandes empreendimentos hidrelétricos no Rio Madeira (UHEs Santo Antônio, licitada em 2007; e Jirau, licitada em 2008) e o avanço em direção à licitação da UHE de Belo Monte/ $\mathrm{PA}$, a qual agregará mais de $11 \mathrm{mil} \mathrm{MW}$ de capacidade instalada ao sistema (Brasil, 2010b, p. 241). 
As polêmicas e a forma como o Governo se posiciona diante dos especialistas que divulgam os problemas relativos à obra, permanecem sem visibilidade nos documentos em todas as mensagens enviadas ao Congresso Nacional.

\section{CONSIDERAÇÕES FINAIS}

A análise de quase cinco mil páginas materializa as vozes institucionais sobre a região, e constata discursos aproximativos e de repetição quanto à exploração e ocupação da região Amazônia em distintos períodos históricos/ ideológicos. As mensagens presidenciais aos parlamentares nos períodos estudados são reducionistas quando situam a região como um vazio que precisa ser vencido em nome de um projeto integrador e desenvolvimentista. Ou ainda, quando acompanhado de uma roupagem de sustentabilidade, o discurso silencia para não suscitar questionamentos.

Dependendo do contexto histórico, o silêncio pode significar a proibição de "falas" ou de temas polêmicos, conforme observado no regime militar, em que as mensagens eram sintéticas para não expor problemas. Por outro lado, no governo de Lula, houve vastos relatórios com detalhamentos, mas sem a escuta dos atores da região.

Assim, a percepção das distorções discursivas - que poderiam estar restritas ao período ditatorial brasileiro - se estende pelos outros dois períodos políticos estudados. A região, fronteira desafiadora de um projeto militar, também tem anulada sua singularidade, sendo sempre citada simultaneamente ao Nordeste, como se os desafios acima do plano piloto de Brasília fossem iguais para realidades tão peculiares. Além disso, as hidrelétricas locais são listadas, de forma misturada aos outros projetos hidrelétricos espalhados pelo país. Tudo é igual para o registro político histórico.

O recorte temático e ideológico, que se faz a partir desse discurso oficial, também mostra que os governos que sucedem os militares permanecem sem dar visibilidade aos impactos socioambientais e aos conflitos que as hidrelétricas causaram e causarão - mesmo utilizando a região como parte de um discurso que pretende assinalar uma preocupação socioambiental.

Nas avaliações ou projeções apresentadas ao Legislativo, o discurso presidencial, cheio de representações sobre o poder da soberania nacional, determinando o futuro da região, também silencia sobre o sujeito amazônico. Esse silêncio é o mesmo em três momentos políticos tão distintos. A região permanece em todos os recortes temporal/ideológicos, objeto de um discurso tecnocrático, em que os governos constroem representações de eficiência e 
competência, produzidas para sua própria legitimação, desconsiderando as peculiaridades locais e os problemas vividos na região.

\section{REFERÊNCIAS}

BRASIL. Biografia Ex-presidentes. [20--]. Disponível em: http://www.biblioteca. presidencia.gov.br/presidencia/ex-presidentes/emilio-medici/biografia Acesso em: 28 jul. 2016.

Entrevista coletiva concedida pelo Presidente da República, Luiz Inácio Lula da Silva, após lançamento do Programa Nacional de Estímulo à Produção de Óleo de Palma e entrega de títulos provisórios de terras e licenciamento ambiental para 3,7 mil agricultores familiares da região de Tomé-Açu-PA. Brasília: Presidência da República, Secretaria de Imprensa, 2010a.

. Mensagem ao Congresso Nacional, 1970 (Presidente Emilio Garrastazu Médici). Brasília: Presidência da República, 1970.

. Mensagem ao Congresso Nacional, 1971 (Presidente Emilio Garrastazu Médici). Brasília: Presidência da República, 1971.

. Mensagem ao Congresso Nacional, 1972 (Presidente Emilio Garrastazu Médici). Brasília: Presidência da República, 1972.

Mensagem ao Congresso Nacional, 1973 (Presidente Emilio Garrastazu Médici). Brasília: Presidência da República, 1973.

Mensagem ao Congresso Nacional, 1974 (Presidente Emilio Garrastazu Médici). Brasília: Presidência da República, 1974.

. Mensagem ao Congresso Nacional, 1986 (Presidente José Sarney): abertura da $4^{a}$ Sessão Legislativa Ordinária da 47a legislatura. Brasília: Presidência da República, 1986.

. Mensagem ao Congresso Nacional, 1987 (Presidente José Sarney): abertura da $1^{\text {a }}$ Sessão Legislativa Ordinária da 48a legislatura. Brasília: Presidência da República, 1987.

.Mensagem ao Congresso Nacional, 1988 (Presidente José Sarney): abertura

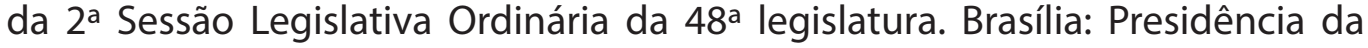
República, 1988.

. Mensagem ao Congresso Nacional, 1989 (Presidente José Sarney): abertura da $3^{a}$ Sessão Legislativa Ordinária da 48a legislatura. Brasília: Presidência da República, 1989. 
. Mensagem ao Congresso Nacional, 1990 (Presidente José Sarney): abertura da 4a Sessão Legislativa Ordinária da 48a legislatura. Brasília: Presidência da República, 1990.

Mensagem ao Congresso Nacional, 2003 (Presidente L. I. Lula da Silva): abertura da 1 a Sessão Legislativa Ordinária da 52 a legislatura. Brasília: Presidência da República, Secretaria Geral da Presidência da República, 2003a.

. Mensagem ao Congresso Nacional, 2004 (Presidente L. I. Lula da Silva):

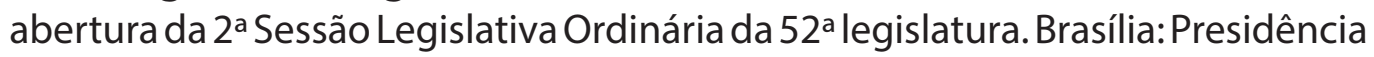
da República, Secretaria Geral da Presidência da República, 2004.

. Mensagem ao Congresso Nacional, 2005 (Presidente L. I. Lula da Silva): abertura da $3^{\text {a }}$ Sessão Legislativa Ordinária da 52a legislatura. Brasília:Presidência da República, Secretaria Geral da Presidência da República, 2005.

. Mensagem ao Congresso Nacional, 2006 (Presidente L. I. Lula da Silva):

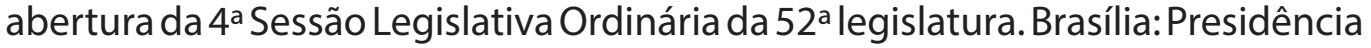
da República, Secretaria Geral da Presidência da República, 2006.

Mensagem ao Congresso Nacional, 2007 (Presidente L. I. Lula da Silva): abertura da 1 a Sessão Legislativa Ordinária da 53a legislatura. Brasília:Presidência da República, Secretaria Geral da Presidência da República, 2007.

. Mensagem ao Congresso Nacional, 2008 (Presidente L. I. Lula da Silva): abertura da $2^{\text {a }}$ Sessão Legislativa Ordinária da 53a legislatura. Brasília:Presidência da República, Secretaria Geral da Presidência da República, 2008.

. Mensagem ao Congresso Nacional, 2009 (Presidente L. I. Lula da Silva): abertura da 3 a Sessão Legislativa Ordinária da 53a legislatura. Brasília:Presidência da República, Secretaria Geral da Presidência da República, 2009.

Mensagem ao Congresso Nacional, 2010 (Presidente L. I. Lula da Silva): abertura da $4^{a}$ Sessão Legislativa Ordinária da 53ª legislatura. Brasília:Presidência da República, Secretaria Geral da Presidência da República, 2010b.

. Pronunciamento do Presidente da República, Luiz Inácio Lula da Silva, na sessão solene de posse no Congresso Nacional. Brasília: Presidência da República, Secretaria de Imprensa e Divulgação, 2003b.

CARTILHA detalha temas sobre a UHE Belo Monte. Blog Belo Monte. 2011. Disponível em: http://blogbelomonte.com.br/2011/05/04/cartilha-detalha-temas-sobrea-uhe-belo-monte Acesso em: 5 set. 2015.

CARVALHO, Georgia. Histórico e impacto das políticas públicas na Amazônia. In: BARROS, Ana Cristina. (Org.). Sustentabilidade e democracia para as políticas públicas na Amazônia. Rio de Janeiro: Fase/Ipam, 2001. 
CHARAUDEAU, Patrick; MAINGUENEAU, Dominique. Dicionário de Análise do Discurso. São Paulo: Contexto, 2006.

Comissão Mundial de Barragens. Barragens e Desenvolvimento: um novo modelo para tomada de decisões - Um sumário. Novembro de 2000. Disponível em: https://www2.mppa.mp.br/sistemas/gcsubsites/upload/41/cmb sumario.pdf Acesso em: 5 set. 2016.

COSTA, Vânia Maria Torres. A Amazônia narrada: entre passado e presente quase nada mudou. In: $6^{\circ}$ Encontro Nacional da Rede Alcar, 2008, Niterói. Anais do $6^{\circ}$ Encontro Nacional da Rede Alcar. Porto Alegre: Alcar, 2008.

FEARNSIDE, Philip Martin. Brazil's Balbina dam: environment versus the legacy of the pharaohs in Amazônia. Environmental Management, New York, v. 13, n. 4, p. 401-423, 1988.

FOLHA DE SÃO PAULO. O Primeiro Choque do Petróleo em 1973. [200-]. Disponível em: http://www1.folha.uol.com.br/folha/dinheiro/petroleo choque1.shtml Acesso em: 4 ago. 2016.

FOUCAULT, Michel. A arqueologia do saber. Rio de Janeiro: Forense Universitária, 1997.

A ordem do discurso. São Paulo: Loyola, 1996.

HAROCHE, Claudine; HENRY, Paul; PÊCHEUX, Michel. La sémantique et la coupure saussurienne: langue, langage, discours. Langages. Paris, número 24, p. 93106, 1971.

HERNÁNDEZ, Francisco del Moral; MAGALHÃES, Sônia Barbosa. Ciência, cientistas e democracia desfigurada: o caso Belo Monte. Novos Cadernos NAEA, Belém, v. 14, n. 1, p. 79-96, jun. 2011.

LOURENÇO, JoséSeixas. Amazônia: trajetória e perspectivas. In:SACHS, Ignacy;WILHEIM, Jorge; PINHEIRO, Paulo Sérgio (Org.). Brasil: um século de transformações. São Paulo: Companhia das Letras, 2001.

OLIVEIRA, R. D. L; MARTINS, R.D.F. A construção dos territórios e os movimentos de atingidos por barragens. In: III Simpósio de Geografia Agrária - II Simpósio Internacional de Geografia Agrária Jornada Ariovaldo Umbelino de Oliveira, 2005, Presidente Prudente. Anais do III Simpósio de Geografia Agrária - II Simpósio Internacional de Geografia Agrária Jornada Ariovaldo Umbelino de Oliveira. Presidente Prudente, p. 1-7, 2005.

ORLANDI, Eni Puccinelli. As formas do silêncio: no movimento de sentidos. Campinas: Unicamp, 1992.

Discurso e leitura. 6. ed. Campinas: Cortez; Unicamp, 2001. 
PÊCHEUX, Michel. Semântica e discurso: uma crítica à afirmação do óbvio. Campinas: Unicamp, 1988.

PHILLIPS, Nelson; HARDY, Cynthia. Discourse analysis. London: Sage Publications, 2002.

PINTO, Lúcio Flávio. A Amazônia em questão: Belo Monte, Vale e outros temas. São Paulo: B4 Editores, 2012a.

De Tucuruí a Belo Monte: a história avança mesmo? Boletim do Museu Paraense Emílio Goeldi. Ciências Humanas, v. 7, n. 3, p. 777-782, 2012b.

Tucuruí: a barragem da ditadura. Belém: Edição Jornal Pessoal, 2011.

PORTAL G1. Lula defende construção da hidroelétrica de Belo Monte. 2010. Disponível em: http://g1.globo.com/mundo/noticia/2010/06/lula-defende-construcaoda-hidroeletrica-de-belo-monte.html Acesso em: 28 jul. 2016.

SANTOS, Sônia Barbosa Magalhães; HERNÁNDEZ, Francisco del Moral. Painel de especialistas: análise crítica do Estudo de Impacto Ambiental do aproveitamento hidrelétrico de Belo Monte. Instituto Socioambiental: Belém, 2009.

SILVA, Fábio Carlos da. Raízes Amazônicas, Universidade e Desenvolvimento Regional. Papers do NAEA, Belém, v. 250, p. 1-15, 2009.

SUDAM. Histórico. [20--]. Disponível em: http://www.sudam.gov.br/index.php/ institucional?id=87 Acesso em: 28 jun. 2016.

TAVARES, Maria da Conceição. Da substituição de importações ao capitalismo financeiro, 4. ed., Rio de Janeiro: Zahar Editores, 1975.

UFPA. Relatório Técnico de Levantamento Topográfico Planialtimetro no Município de Altamira: caracterização da Cota 100 no Núcleo Urbano. 2010. Disponível em: http://www.prpa.mpf.mp.br/news/2012/arquivos/Relatrio\%20tecnico\%20 Topografia\%20Cota\%20100\%20Altamira\%20Retificado.pdf/view Acesso em: 4 ago. 2016.

XINGU VIVO. Cronologia de Belo Monte. Xingu Vivo. [S.d.]. Disponível em: http://www. xinguvivo.org.br/x23/?page id=3012 Acesso em: 5 set. 2015. 
Recebido em: 10/8/2016

Aceito em: 23/9/2016

Alda Cristina Costa <aldacristinacosta@gmail.com>

Programa de Pós-Graduação em Comunicação, Cultura e Amazônia (PPGCom/Universidade Federal do Pará).

Rua Augusto Corrêa, n. 1 - Guamá

66075-110 - Belém (PA) - Brasil

Ivana Cláudia Oliveira <ivana.professora@gmail.com>

Universidade da Amazônia (Unama)

Avenida Alcindo Cacela, 287 - Umarizal

66065-219 - Belém (PA) - Brasil

Nírvea Ravena <niravena@uol.com.br>

Programa de Pós-Graduação em Desenvolvimento Sustentável do Trópico Úmido-PPGDSTU do Núcleo de Altos Estudos Amazônicos (NAEA/UFPA).

Universidade Federal do Pará

Avenida Perimetral, n. 1 - Guamá

66075-750 - Belém (PA) - Brasil 